\title{
ADOPSI PETANI TERHADAP TEKNOLOGI JAJAR LEGOWO PADI SAWAH DI KELURAHAN RIMBO KEDUI KECAMATAN SELUMA SELATAN KABUPATEN SELUMA
}

\author{
Yeni Herlina $^{1)}$, Mohammad Chozin ${ }^{2)}$, Atra Romeida ${ }^{2)}$ \\ ${ }^{1)}$ Dinas Pertanian Seluma Pemerintahan dan Kesejahteraan Rakyat Setda Provinsi Bengkulu \\ ${ }^{2)}$ Jurusan Agroteknologi Fakultas Pertanian Universitas Bengkulu
}

\begin{abstract}
ABSTRAK
Program GP-PTT sebagai kelanjutan dari Program SL-PTT yang menerapkan teknologi jajar legowo merupakan suatu upaya yang telah dilakukan oleh pemerintah untuk meningkatkan produktifitas lahan persawahan yang ada melalui pemberdayaan petani. Untuk mengetahui tingkat keberhasilan teknologi jajar legowo dalam program tersebut maka perlu dievaluasi tingkat penerapan komponen-komponennya yang dipengaruhi oleh berbagai faktor. Tujuan dari penelitian ini adalah untuk mengidentifikasi dan mengevaluasi faktor-faktor sosial ekonomi (umur, pendidikan, luas lahan, status kepemilikan lahan, jumlah anggota keluarga, pengalaman usahatani, pendapatan) dan persepsi petani terhadap teknologi jajar legowo padi sawah di Kelurahan Rimbo Kedui kecamatan Seluma Selatan Kabupaten Seluma. Penentuan daerah penelitian dilakukan secara sengaja yaitu petani padi sawah yang telah mengikuti kegiatan program SL-PTT dan GP-PTT yang menerapkan teknologi jajar legowo. Data yang digunakan adalah data primer dan data sekunder yang diperoleh dari hasil survei di lapangan. Metode penentuan sampel menggunakan teori yang dikemukakan oleh Arikunto Suharsimi untuk jumlah populasi diatas 100 maka diperoleh sampel sebanyak 40 orang petani. Penentuan faktor-faktor yang memetakan tingkat adopsi dilakukan dengan analisis regresi logistik dengan transformasi logit. Hasil analisis secara deskriptif menunjukkan bahwa sebanyak 98,82\% petani mempunyai persepsi baik terhadap sifat inovasi teknologi jajar legowo dan 62,5\% petani menerapkan sesuai anjuran sedangkan 37,5\% petani menerapkan tidak sesuai anjuran. Hasil analisis logistik menunjukkan bahwa pendidikan dan pendapatan usahatani merupakan faktor penting dalam menentukan tingkat adopsi teknologi jajar legowo oleh petani.
\end{abstract}

Kata Kunci : adopsi, petani, jajar legowo, padi sawah

\section{PENDAHULUAN}

Padi merupakan tanaman yang memiliki arti strategis bagi bangsa Indonesia. Beras yang berasal dari padi menjadi bahan pangan pokok bagi lebih dari $90 \%$ penduduk Indonesia (Pusdatin, 2013). Padi juga merupakan komoditas pertanian yang menjadi sumber penghidupan bagi lebih dari 20 juta jiwa petani (BPS, 2013). Karena itu, penyediaan padi menjadi senantiasa menjadi agenda prioritas pembangunan pertanian.
Luas lahan panen padi dalam kurun waktu tahun 2012-2015 meningkat ratarata 2,67\% per tahun. Di sisi lain kebutuhan beras semakin meningkat. Rata-rata kebutuhan beras tahun 2011-2015 untuk rumah tangga 24.593 .627 ton dengan ratarata peningkatan $0,93 \%$, sedangkan untuk non rumah tangga 7.184.479 ton dengan peningkatan rata-rata $-5,81 \%$ (Pusdatin, 2016).

Kelurahan Rimbo Kedui pada tahun 2010 menjadi sentra produksi padi di Kabupaten Seluma dengan peruntukan lahan persawahan mencapai 505,00 ha. Lahan 
persawahan yang luas serta ketersediaan air yang dapat mencukupi kebutuhan tanaman sepanjang tahun menjadikan daerah ini sebagai salah satu sumber pangan di Kabupaten Seluma. Seiring waktu luas lahan mengalami penyusutan akibat adanya alih fungsi lahan untuk perkebunan sawit dan produktifitas lahan yang masih rendah mengakibatkan menurunnya produksi padi (Damiri dan Yartiwi, 2012). Luas lahan persawahan di Kelurahan Rimbo Kedui berdasarkan data tahun 2015 sebanyak 427,35 ha, jumlah ini mengalami penurunan dibandingkan tahun 2010 sebanyak 505 ha (BP3K Sukarami, 2018). Tahun 2010-2015 produksi padi Kabupaten Seluma rata rata 88,308 ton GKG dengan laju pertumbuhan $\quad-6,30 \%$ sedangkan rata-rata Provinsi Bengkulu yaitu 679,202 dengan laju pertumbuhan 2,28\% (BPS, 2016). Produksi padi harus ditingkatkan, untuk itu perlu adanya suatu terobosan sebagai upaya untuk meningkatkan produktifitas lahan persawahan yang masih ada.

Upaya peningkatan produktifitas padi di Kelurahan Rimbo Kedui telah dilakukan melalui penekanan penerapan inovasi teknologi pendekatan Pengelolaan Tanaman Terpadu (PTT) sejak Tahun 2010. Langkah awal yang telah dilakukan oleh pemerintah yaitu dengan melaksanakan Program Sekolah Lapang Pengelolaan Tanaman Terpadu (SL-PTT). SL-PTT yang merupakan gerakan awal dari Program Gerakan Penerapan Pengelolalan Tanaman Terpadu (GP-PTT) yang menerapkan teknologi Jajar Legowo (Jarwo) merupakan strategi peningkatan produktivitas padi. Pada awalnya program SL-PTT dimaksudkan sebagai suatu tempat pendidikan non formal bagi petani untuk meningkatkan pengetahuan dan keterampilan dalam mengatasi permasalahan, mengambil keputusan dan menerapkan teknologi, sehingga teknologi yang digunakan spesifik lokasi, berwawasan lingkungan, efisien, berproduktivitas tinggi dan berkelanjutan (Sembiring dan Sarlan, 2008).
PTT yang menerapkan teknologi Jarwo merupakan pendekatan dalam penerapan komponen teknologi yang saling menunjang dengan mengutamakan pertimbangan karakteristik biofisik lingkungan, kondisi sosial, ekonomi dan budaya petani setempat selalu dijadikan dasar dalam perakitan teknologi. Melalui Program PTT diharapkan produktivitas padi dan pendapatan petani meningkat namun lingkungan tetap terjaga dan sistem produksi berkelanjutan (Sembiring dan Sarlan, 2008).

Teknologi Jarwo yang diterapkan melalui pendekatan PTT mampu meningkatkan produktivitas padi sawah. Hal tersebut sebagaimana diketahui melalui hasil penelitian yang telah dilakukan oleh Damiri dan Yartiwi (2010) di Kelurahan Rimbo Kedui yang menyatakan bahwa dengan penerapan inovasi teknologi pendekatan PTT dapat meningkatkan produktivitas padi sebesar 6,51 ton/ha gabah kering panen lebih tinggi bila dibandingkan dengan produktivitas padi yang menerapkan teknologi eksisting sebesar 3,50 ton/ha gabah kering panen.

PTT padi sawah yang menerapkan teknologi Jarwo merupakan strategi pengelolaan tanaman padi yang bertujuan meningkatkan produktivitas dan pendapatan petani padi sawah serta melestarikan lingkungan produksi dengan memperhatikan sumberdaya alam secara bijak melalui pengelolaan lahan, air, tanaman, OPT, dan iklim secara terpadu (Balitbangtan, 2011). Komponen yang diimplementasikan dalam teknologi Jarwo meliputi ; pembuatan baris tanaman, penanaman, pengairan, pemupukan, penyiangan, serta pengendalian hama dan penyakit.

Program GP-PTT merupakan tindak lanjut dari Program SL-PTT telah selesai dilaksanaan. Namun, tingkat penerapan komponen-komponen teknologi Jarwo oleh setiap petani tentunya tidak sama, hal tersebut dipengaruhi oleh berbagai faktor. Untuk mengetahui tingkat keberhasilan teknologi Jarwo dalam Program GP-PTT maka perlu dievaluasi. Ukuran yang umum digunakan dalam mengukur keberhasilan 
adalah tingkat adopsi berikut faktor-faktor yang mempengaruhinya.

Penelitian ini bertujuan untuk mengidentifikasi dan mengevaluasi faktorfaktor yang mempengaruhi adopsi petani terhadap teknologi jajar legowo padi sawah di Kelurahan Rimbo Kedui Kecamatan Seluma Selatan Kabupaten Seluma.

\section{METODE PENELITIAN}

Penelitian ini dilaksanakan di Kelurahan Rimbo Kedui Kecamatan Seluma Selatan Kabupaten Seluma pada bulan Mei sampai dengan bulan Juni 2018. Populasi yang dijadikan objek penelitian yaitu petani padi sawah yang telah mengikuti kegiatan SL-PTT dan GP-PTT yang menerapkan teknologi jajar legowo. Metode penentuan sampel menggunakan teori yang dikemukakan oleh Arikunto Suharsimi (2010) untuk jumlah populasi diatas 100 maka diperoleh sampel sebanyak 40 orang petani.

Populasi penelitian ini adalah 160 Orang petani yang terhimpun dalam $7 \mathrm{ke}$ lompok tani pangan kemudian ditentukan sampel secara acak sebanyak $25 \%$ dari total populasi, sehingga sampel yang dijadikan sebanyak 25\% x 160 Orang $=40$ orang.

Pengumpulan data dikategorikan sebagai data primer dan data sekunder. Data primer yaitu data yang diperoleh/dikumpulkan secara langsung melalui wawancara responden dengan menggunakan kuesioner sebagai bantuan. Data primer yang dikumpulkan dalam penelitian ini antara lain; 1) umur, 2) pendidikan formal, 3) luas penguasan lahan, 4) Status Kepemilikan lahan, 5) tingkat pendapatan, 6) persepsi petani tentang teknologi jajar legowo (keuntungan relatif, kesesuaian, kerumitan dan ketercobaan/ keteramatan). Data sekunder adalah data yang dikumpulkan dari instansi atau lembaga yang berkaitan dengan penelitian, dengan cara mencatat langsung data yang bersumber dari dokumentasi yang ada.
Teknik dan pengumpulan data yang digunakan dalam penelitian ini terdiri dari wawancara, observasi dan pencatatan.

Riduwan dan Akdon (2008), menyatakan untuk menghitung nilai persepsi maka setiap jawaban dari setiap pertanyaan dihubungkan dengan bentuk pernyataan atau dukungan. ponden selanjutnya dilakukan pembobotan dengan nilai sebagai berikut setuju (3), ragu-ragu (2), tidak setuju (1). Analisis data yang digunakan merupakan analisis deskriptif yang menggunakan Linkert Scale (skala linkert).

Faktor-faktor yang mempengaruhi petani mengadopsi teknologi jajar legowo dianalisis secara kuantitatif Analisis kuantitatif dianalisis untuk mengetahui hubungan antara variabel tak bebas (Y) yaitu adopsi petani terhadap teknologi jajar legowo dan delapan variabel bebas (X) yang merupakan data karakteristik responden. Data karakteristik responden terdiri atas umur $\left(\mathrm{X}_{1}\right)$, tingkat pendidikan $\left(\mathrm{X}_{2}\right)$, luas penguasaan lahan $\left(\mathrm{X}_{3}\right)$, status kepemilikan lahan $\left(\mathrm{X}_{4}\right)$, Jumlah Anggota Keluarga $\left(\mathrm{X}_{5}\right)$, Pengalaman berusahatani $\left(\mathrm{X}_{6}\right)$ dan tingkat pendapatan $\left(\mathrm{X}_{7}\right)$. Untuk menganalisis variabel tak bebas $(\mathrm{Y})$ yaitu adopsi petani terhadap teknologi jajar legowo dan delapan variabel bebas (X) yang merupakan data karakteristik responden digunakan model regresi logit biner.

$\mathrm{Yi}=\mathrm{P}\left(\mathrm{X}_{\mathrm{i}}\right) / 1-\mathrm{P}\left(\mathrm{X}_{\mathrm{i}}\right)=\mathrm{bo}+\mathrm{b} 1 \mathrm{X} 1+\mathrm{b} 2 \mathrm{X} 2+$ b3X

$$
+b 4 X 4+b 5 X 5+b 6 X 6+b 7 X 7
$$

Keterangan :

$\mathrm{Y}_{\mathrm{i}}=$ Adopsi

$\mathrm{X}_{1}=$ Umur responden (tahun)

$\mathrm{X}_{2} \quad=$ Tingkat pendidikan (tahun)

$\mathrm{X}_{3} \quad=$ Luas penguasaan lahan (hektar)

$\mathrm{X}_{4} \quad=$ Status kepemilikan Lahan

$\mathrm{X}_{5} \quad$ = Jumlah anggota keluarga (jiwa)

$\mathrm{X}_{6} \quad=$ Pengalaman usahatani (tahun)

$\mathrm{X}_{7} \quad=$ Pendapatan (Rp/musim tanam)

$\mathrm{e}_{\mathrm{i}} \quad=$ Error

$\mathrm{b}_{0} \quad=$ Konstanta

$b_{1} . . b_{4}=$ parameter dugaan (koefisien)

$\mathrm{P}\left(\mathrm{X}_{\mathrm{i}}\right)$ adalah peluang adopsi sesuai anjuran terhadap teknologi jajar legowo, sebagai kebalikan dari $1-\mathrm{P}\left(\mathrm{X}_{\mathrm{i}}\right)$ sebagai 
peluang adopsi tidak sesuai anjuran. Oleh karenanya, ln $\left[\mathrm{P}\left(\mathrm{X}_{\mathrm{i}}\right) / 1-\mathrm{P}\left(\mathrm{X}_{\mathrm{i}}\right)\right]$ secara sederhana merupakan logaritma natural dari perbandingan antara peluang adopsi sesuai anjuran dengan peluang adopsi tidak sesuai anjuran. Oleh karenanya, koefisien dalam persamaan (4) ini menunjukkan pengaruh dari variabel $\mathrm{X}_{\mathrm{i}}$ terhadap peluang relatif adopsi sesuai anjuran dibandingkan dengan adopsi tidak sesuai anjuran terhadap teknologi jajar legowo. Dalam penelitian ini, data diolah menggunakan perangkat lunak SPSS (Statistic Program for Social Science).

\section{HASIL DAN PEMBAHASAN}

Tabel 1. Karakteristik responden

\begin{tabular}{|c|c|c|c|c|c|}
\hline Variabel & Skala & $\begin{array}{l}\text { Proporsi } \\
\text { responden }\end{array}$ & Variabel & Skala & $\begin{array}{c}\text { Proporsi } \\
\text { responden }\end{array}$ \\
\hline Umur & $>51,34$ & $12,5 \%$ & $\begin{array}{l}\text { Jumlah } \\
\text { Anggota }\end{array}$ & $>3$ & $55 \%$ \\
\hline & $\begin{array}{c}40,67-51,33 \\
<40,67\end{array}$ & $\begin{array}{c}72,5 \% \\
15 \%\end{array}$ & Keluarga & $\begin{array}{l}2-3 \\
<2\end{array}$ & $\begin{array}{c}42,5 \% \\
2,5 \%\end{array}$ \\
\hline Pendidikan & $\begin{array}{c}>10 \\
8-10 \\
<8\end{array}$ & $\begin{array}{c}17,5 \% \\
52,5 \% \\
30 \%\end{array}$ & $\begin{array}{l}\text { Pengalaman } \\
\text { Usahatani }\end{array}$ & $\begin{array}{c}>24,3 \\
16,3-24,3 \\
<16,3\end{array}$ & $\begin{array}{c}27,5 \% \\
52,5 \% \\
20 \%\end{array}$ \\
\hline Luas Lahan & $\begin{array}{c}>0,75 \\
0,5-0,75\end{array}$ & $\begin{array}{c}15 \% \\
77,5 \%\end{array}$ & Pendapatan & $\begin{array}{l}>16.640 .000 \\
10.580 .000- \\
16.640 .000\end{array}$ & $\begin{array}{c}15 \% \\
62,5 \%\end{array}$ \\
\hline $\begin{array}{l}\text { Status kepemilikan } \\
\text { Lahan }\end{array}$ & $\begin{array}{c}\text { Milik } \\
\text { Bukan milik }\end{array}$ & $\begin{array}{l}75 \% \\
25 \%\end{array}$ & & & \\
\hline
\end{tabular}

Tabel 2. Persepsi Responden terhadap Sifat Inovasi Teknologi Jarwo

\begin{tabular}{llccccc}
\hline & & \multicolumn{4}{c}{ Sifat Inovasi Teknologi Jarwo (Persentase Responden) } \\
\cline { 3 - 7 } No & Persepsi & $\begin{array}{c}\text { Keuntungan } \\
\text { Nisbi }\end{array}$ & $\begin{array}{c}\text { Kesesuaia } \\
\text { n Inovasi }\end{array}$ & $\begin{array}{c}\text { Kerumitan } \\
\text { Inovasi }\end{array}$ & $\begin{array}{c}\text { Kemampua } \\
\text { n diuji } \\
\text { coba }\end{array}$ & $\begin{array}{c}\text { Kemampua } \\
\text { n Diamati }\end{array}$ \\
\hline 1 & Setuju & 90 & 90 & 100 & 90 & 90 \\
2 & Ragu-ragu & 10 & 10 & 0 & 10 & 10 \\
3 & Tidak setuju & 0 & 0 & 0 & 0 & 0 \\
\hline
\end{tabular}

Persepsi dari 40 responden terhadap teknologi Jarwo (Tabel 2) dikelompokkan berdasarkan 5 sifat inovasi teknologi

Jarwo. Berdasarkan analisa hasil kuisioner menggunakan Skala linkert (Riduwan dan Akdon, 2008), secara keseluruhan persepsi petani responden

\section{Karakteristik Responden}

Karakteristik petani yang menjadi responden yang diamati dalam penelitian ini terdiri dari umur petani, pendidikan, luas penguasaan lahan, status kepemilikan lahan, jumlah anggota keluarga, pengalaman usahatani, pendapatan, serta persepsi petani terhadap teknologi Jarwo yang diperoleh dengan mengajukan pertanyaan terstruktur dan pengamatan langsung. Dengan demikian diperoleh skor untuk masing-masing variabel bebas. Secara deskriptif dapat dijelaskan sebagai berikut (Tabel 1): 98,82\% menyatakan baik. Hal tersebut diduga petani setuju dan memiliki persepsi yang baik dikarenakan mayoritas petani menganggap bahwa inovasi teknologi Jarwo padi sawah menguntungkan, sesuai dengan nilai, pengalaman dan kebutuhan yang diperlukan oleh penerima, memiliki tingkat kerumitan yang rendah, mudah 
untuk diterapkan dan mudah untuk dicoba serta dapat diamati hasilnya. Sedangkan $1,78 \%$ menyatakan ragu-ragu.

Banyak faktor yang menjadi pertimbangan seorang petani sebelum membangun suatu persepsi terhadap informasi teknologi. Persepsi petani bisa positif, negatif atau netral. Persepsi yang positif akan mendorong untuk adopsi dan sebaliknya jika negatif maka petani akan menolak teknologi yang ditawarkan, namun jika netral bukan berarti tidak mengambil keputusan tetapi tidak memberikan reaksi menerima atau menolak teknologi tersebut (Hendayana, 2014).

\section{Adopsi Petani Terhadap Teknologi Jarwo}

Adopsi merupakan suatu proses mental untuk mengambil keputusan untuk menerima atau menolak dalam penerapan suatu inovasi teknologi baru. Dalam penerimaan atau penerapan teknologi baru yang disampaikan kepada petani tentu tingkat penerapannya berbeda. Dari keseluruhan tingkat penerapan petani terhadap teknologi Jarwo di atas maka dapat dilihat tingkat adopsi petani terhadap teknologi Jarwo. Komponen parameter adopsi teknologi Jarwo dapat dilihat pada Tabel 3.

Tingkat adopsi petani terhadap teknologi Jarwo diukur berdasarkan 6 komponen parameter adopsi Jarwo. Dari 40 responden ternyata $65 \%$ petani sudah mengadopsi komponen pembuatan baris tanam sesuai anjuran, $62,5 \%$ petani sudah mengadopsi komponen penanaman dan komponen pengairan sesuai anjuran, $77,5 \%$ petani sudah mengadopsi komponen penyiangan sesuai anjuran, dan $60 \%$ petani sudah mengadopsi pengendalian HPT sesuai anjuran. Sementara pada komponen pemupukan $60 \%$ petani sudah menerapkan tetapi belum sesuai anjuran. 5 dari 6 komponen parameter sudah diadopsi sesuai anjuran, dengan demikian secara keseluruhan komponen Jarwo sudah diadopsi sesuai anjuran oleh petani.
Faktor-faktor Sosial Ekonomi yang mempengaruhi Adopsi Teknologi Jarwo Padi sawah

Hasil estimasi fungsi regresi logit secara keseluruhan terhadap variabel bebas (Tabel 4), untuk menguji variable yang diduga berpengaruh nyata terhadap peluang adopsi sesuai anjuran maka digunakan uji signifikan dari parameter koefisien secara parsial. Dari nilai signifikan output program SPSS (Statistical Package for the Social Science), diketahui bahwa ada dua variabel yang berpengaruh nyata terhadap peluang adopsi sesuai anjuran yaitu variabel X2 (pendidikan) dan variabel X7 (pendapatan). Sedangkan variabel yang lain yaitu X1 (umur), X3 (luas lahan), X4 (status kepemilikan lahan), X5 (jumlah anggota keluarga) dan X6 (pengalaman usahatani) berpengaruh tidak nyata terhadap peluang adopsi sesuai anjuran. 
P-ISSN: 2302- 6715

E- ISSN: 2654-7732

Tabel 3. Tingkat Adopsi Teknologi Jarwo

\begin{tabular}{|c|c|c|c|c|c|}
\hline $\mathrm{Y}$ & Komponen Adopsi & Persentase $(\%)$ & Jumlah (Jiwa) & Kisaran & Interval kelas \\
\hline \multirow{3}{*}{ Y1 } & Pembuatan baris tanam & & & & \\
\hline & Sesuai anjuran > 6 & 65 & 26 & $3-9$ & 6 \\
\hline & Tidak sesuai anjuran $\leq 6$ & 35 & 14 & & \\
\hline \multirow[t]{3}{*}{$\mathrm{Y} 2$} & Penanaman & & & & \\
\hline & Sesuai anjuran $>8$ & 62,5 & 25 & $4-12$ & 8 \\
\hline & Tidak sesuai anjuran $\leq 8$ & 37,5 & 15 & & \\
\hline \multirow[t]{3}{*}{ Y3 } & Pengairan & & & & \\
\hline & Sesuai anjuran $>2$ & 62,5 & 25 & $1-3$ & 2 \\
\hline & Tidak sesuai anjuran $\leq 2$ & 37,5 & 15 & & \\
\hline \multirow[t]{3}{*}{ Y4 } & Pemupukan & & & & \\
\hline & Sesuai anjuran $>6$ & 40 & 16 & 3-9 & 6 \\
\hline & Tidak sesuai anjuran $\leq 6$ & 60 & 24 & & \\
\hline \multirow[t]{3}{*}{ Y5 } & Penyiangan & & & & \\
\hline & Sesuai anjuran > 2 & 77,5 & 31 & $1-3$ & 2 \\
\hline & Tidak sesuai anjuran $\leq 2$ & 22,5 & 9 & & \\
\hline \multirow[t]{6}{*}{ Y6 } & Pengendalian HPT & & & & \\
\hline & Sesuai anjuran > 4 & 60 & 24 & $5-6$ & 4 \\
\hline & Tidak sesuai anjuran $\leq 4$ & 40 & 16 & & \\
\hline & Total Skor Adopsi & & & & \\
\hline & Sesuai anjuran > 28 & 62,5 & 25 & $14-42$ & 28 \\
\hline & Tidak sesuai anjuran $\leq 28$ & 37,5 & 15 & & \\
\hline
\end{tabular}

Tabel 4. Hasil Estimasi Fungsi Regresi Logit

\begin{tabular}{clccc}
\hline No & \multicolumn{1}{c}{ Variabel Bebas } & Koefisien & Sig & Odds ratio \\
\hline 1 & X1 (umur) & $-1,84$ & 0,45 & 0,16 \\
2 & X2 (Pendidikan) & 3,85 & $0,03^{*}$ & 47,03 \\
3 & X3 (Luas lahan) & 1,04 & 0,94 & 2,82 \\
4 & X4 (Status kepemilikan lahan) & 2,17 & 0,32 & 8,79 \\
5 & X5 (Jumlah anggota keluarga) & 0,97 & 0,58 & 2,65 \\
6 & X6 (Pengalaman usahatani) & $-1,42$ & 0,26 & 0,24 \\
7 & X7 (Pendapatan) & 4,18 & $0,05^{*}$ & 65,24 \\
\hline & Konstanta & $-15,10$ & & \\
& Kelayakan model (Nagelkerke $\mathrm{R}^{2}$ ) & 0,855 & & \\
\hline
\end{tabular}

Kedelapan variabel bebas dengan melihat nilai Nagelkerke $\mathrm{R}^{2}$ (kelayakan model) mampu untuk menjelaskan variabel adopsi dengan nilai sebesar $85,5 \%$. Dari output SPSS diperoleh persamaan model regresi logit biner adopsi petani padi sawah terhadap teknologi Jarwo sebagai berikut :

$$
\begin{gathered}
\mathrm{Yi}=\ln \frac{\mathrm{P}(\mathrm{Xi})}{1-\mathrm{P}(\mathrm{Xi})}=-15,10-1,84 \mathrm{X} 1+3,85 \mathrm{X} 2 \\
+ \\
1,04 \mathrm{X} 3+2,17 \mathrm{X} 4+0,97 \mathrm{X} 5-1,42 \mathrm{X} 6 \\
+4,18 \mathrm{X} 7
\end{gathered}
$$

$\mathrm{X} 1=$ Umur (tahun)

$\mathrm{X} 2$ = Pendidikan (tahun)

X3 = Luas Lahan (ha)

X4 = Status Kepemilikan Lahan

X5 = Jumlah Anggota Keluarga (jiwa)

$\mathrm{X} 6=$ Pengalaman Usahatani (tahun)

$\mathrm{X} 7=$ Pendapatan $(\mathrm{Rp})$

Dilihat dari persamaan model regresi logit biner di atas ternyata variabel yang paling berpengaruh sampai variabel yang kurang berpengaruh berdasarkan besarnya konstanta secara berurutan yaitu X7 (pendapatan) sebesar 4,18; X2 
(pendidikan) sebesar 3,85; X4 (status kepemilikan lahan) sebesar 2,17; X1 (umur) sebesar 1,84; X6 (pengalaman usahatani) sebesar 1,42; X3 (luas lahan) sebesar 1,04 dan X5 (jumlah anggota keluarga) sebesar 0,97. Ternyata variabel X7 (pendapatan) paling berpengaruh, hal tersebut dikarenakan sebelum mengadopsi suatu teknologi inovasi baru, petani pada umumnya mempertimbangkan faktor keuntungan melalui pendapatan yang diperoleh dari hasil produksi yang dikalikan harga jual produk. Jika pendapatan yang diperoleh lebih tinggi dari sebelumnya maka petani akan mengadopsi teknologi baru tersebut.

Variabel kedua yang paling berpengaruh berikutnya yaitu X2 (pendidikan), karena pada umumnya petani dengan pendidikan yang lebih tinggi mempunyai pola fikir dalam bersikap dan bertindak lebih maju sehingga lebih terbuka dan mudah menerima adanya perubahan. Menurut Mardikato (1994), keterbatasan penerapan teknologi oleh petani kecil terutama disebabkan oleh rendahnya tingkat pendidikan. Oleh sebab itu rendahnya pendidikan petani menjadi hambatan adopsi teknologi baru dan sebaliknya pendidikan dan keterampilan yang memadai dapat memperlancar proses adopsi teknologi baru di pedesaan.

Dilihat dari konstanta dari persamaan model regresi logit biner ketujuh variabel $\mathrm{X} 1$ (umur), X2 (pendidikan), X3 (luas lahan), X4 (status kepemilikan lahan), X5 (jumlah anggota keluarga), X6 (pengalaman usahatani) dan X7 (pendapatan usahatani), ternyata variabel yang paling berpengaruh nyata atau memiliki pengaruh yang sangat besar terhadap adopsi petani sesuai anjuran secara beurutan adalah variabel X7 (pendapatan) dan variabel X2 (pendidikan). Sedangkan variabel yang berpengaruh tidak nyata atau memiliki pengaruh yang kecil terhadap adopsi petani sesuai anjuran secara beurutan adalah X4 (status kepemilikan lahan), X1 (umur), X6 (pengalaman usahatani), X3 (luas lahan), dan X5 (jumlah anggota keluarga).

\section{Variabel Lingkungan Sosial Ekonomi dan Budaya}

Produktivitas padi yang dicapai dengan menggunakan teknologi existing sebelum menggunakan teknologi Jarwo rata-rata hanya sebesar 3,50 ton/ha per musim tanam. Setelah petani menggunakan teknologi Jarwo, produktivitas padi yang dicapai meningkat menjadi rata-rata 6,51 ton/ha per musim tanam (Damiri dan Yartiwi, 2010). Hasil produksi yang diperoleh petani jika dikalikan dengan harga jual dan dikurangi dengan biaya produksi maka akan diperoleh pendapatan. Dengan meningkatnya produktivitas padi maka pendapatan petani juga akan meningkat. Keuntungan yang diperoleh dari usahatani padi akan semakin besar jika pendapatan yang yang diperoleh semakin tinggi. Pendapatan dari penerapan teknologi Jarwo yang lebih tinggi jika dibandingkan dengan pendapatan sebelum menerapkan teknologi Jarwo akan membangun persepsi positif petani terhadap teknologi Jarwo.

Sifat inovasi teknologi diantaranya keuntungan nisbi, kesesuaian inovasi, kerumitan inovasi, kemampuan diujicoba dan kemampuan diamati. Sifat inovasi teknologi yang paling utama dapat membangun persepsi positif dari petani yaitu keuntungan nisbi jika menerapkan suatu teknologi lebih menguntungkan atau tidak dari segi pendapatan yang diperoleh petani. Persepsi petani terhadap sifat inovasi teknologi Jarwo, sebanyak $90 \%$ petani mempunyai persepsi setuju terhadap sifat inovasi keuntungan nisbi. Hal tersebut diduga petani telah merasakan keuntungan dalam menerapkan Teknologi Jarwo melalui peningkatan produktivitas padi yang pada akhirnya meningkatkan pendapatan petani. Secara sosial teknologi Jarwo telah mampu membentuk persepsi petani menjadi positif karena merasakan petani telah 
merasakan keuntungan dari penerapan teknologi Jarwo.

Persepsi positif dari petani akan mendorong petani untuk mengadopsi suatu teknologi. Adopsi petani terhadap teknologi Jarwo, sebanyak $62,5 \%$ petani mengadopsi teknologi Jarwo sesuai anjuran. Sementara 37,5\% mengadopsi teknologi Jarwo tetapi belum sesuai anjuran. Keputusan petani padi sawah Kelurahan Rimbo Kedui untuk mengadopsi teknologi Jarwo telah mampu mengubah budaya bercocok tanam padi yang selama ini petani terapkan ke budaya baru yaitu budaya bercocok tanam padi dengan menggunakan Jarwo. Petani yang dilibatkan dalam program SL-PTT dan GP-PTT adalah sebanyak 160 orang petani, namun setelah program selesai dilaksanakan hanya $62,5 \%$ saja yang menerapkan sesuai anjuran. Hal tersebut diduga disebabkan beberapa faktor antara lain adanya keterbatasan biaya terutama terhadap komponen pemupukan, karena selama program SL-PTT dan program GPPTT berjalan pemerintah memberikan bantuan bibit, pupuk dan sarana produksi lainnya. Sedangkan saat ini petani hanya dibantu bibit unggul berlabel saja. untuk kedepannya agar petani dapat mengadopsi sesuai anjuran bedasarkan komponen yang tidak diadopsi sesuai anjuran yaitu pemupukan, maka diharapkan agar pemerintah memberikan bantuan berupa pupuk, saprodi dan memperbanyak program pelatihan bagi petani. Sehingga kedepannya diharapkan tingkat adopsi petani sesuai anjuran minimal mencapai $80 \%$, karena sebanyak $37,5 \%$ petani sebenarnya telah mengadopsi Teknologi Jarwo namun belum sesuai anjuran.

\section{KESIMPULAN}

Berdasarkan hasil penelitian dan pembahasan yang telah dilakukan, maka dapat disimpulkan sebagai berikut :

1. Hampir seluruh petani mempunyai persepsi baik terhadap teknologi jajar legowo yaitu sebesar $98,82 \%$ sedangkan $1,18 \%$ menyatakan ragu- ragu. Persepsi yang baik dari petani tersebut akan mendorong petani untuk mengadopsi teknologi jajar legowo sesuai anjuran.

2. Penerapan komponen teknologi jajar legowo terdiri dari 6 komponen, 5 komponen diantaranya sudah diterapkan sesuai anjuran yaitu pembuatan baris tanam, penanaman, pengairan, penyiangan dan pengendalian HPT. Sedangkan komponen pemupukan sudah diterapkan tetapi belum sesuai anjuran.

3. Adopsi petani berdasarkan tingkat penerapan petani terhadap komponen parameter adopsi teknologi Jarwo, sebanyak $62,5 \%$ petani sudah mengadopsi sesuai anjuran dan adopsi tidak sesuai anjuran sebesar 37,5\%. Secara keseluruhan komponen teknologi jajar legowo sudah diadopsi sesuai anjuran oleh petani.

4. Faktor-faktor sosial ekonomi yang mempengaruhi adopsi petani sesuai anjuran terhadap teknologi jajar legowo yaitu pendapatan usahatani dan pendidikan formal.

\section{DAFTAR PUSTAKA}

Badan Pusat Statistik. 2013. Sensus Pertanian : Jumlah Petani Menurut Provinsi (ha), 1993-2015. Badan Pusat Statistik. Jakarta.https://ww.bps.go.id/linkTableDi namis/view/id/865 (15 september 2018)

Badan Pusat Statistik. 2016. Produksi Padi Menurut Kabupaten/Kota di Propinsi Bengkulu Tahun 2010 -2015 (Ton GKG). Badan Pusat Statistik. Bengkulu. https://bengkulu.bps.go.id/statistict able/2016/03/17/256 (15 september 2018)

Balitbangtan Kementerian Pertanian. 2011. Petunjuk Teknis Lapangan Pengelolaan Tanaman Terpadu (PTT) Padi Sawah. Balitbangtan Kementerian Pertanian. Jakarta 
BP3K Sukarami. 2018. Programa Penyuluhan Pertanian BP3K Sukarami Kecamatan Seluma Selatan Kabupaten Seluma. BP3K Sukarami. Seluma

Damiri, A dan Yartiwi. 2010. Peluang Peningkatan Produksi Padi di Kabupaten Seluma ; Studi Kasus Lahan Sawah Kelurahan Rimbo Kedui Kecamatan Seluma Selatan. BPTP. Bengkulu..

Hendayana, R. 2014. Persepsi dan Adopsi Teknologi ; Teori dan Praktek Pengukuran. BPTP. Bogor.

Mardikanto, T. 1994. Bunga Rampai Pembangunan Pertanian. Penerbit University Press. Surakarta.

Pusdatin Kementerian Pertanian. 2013. Buletin Konsumsi Pangan. Pusdatin Kementerian Pertanian. Jakarta.

Pusdatin Kementerian Pertanian. 2016. Outlook Komoditas Pertanian Subsektor Tanaman Pangan : Komoditas Tanaman Padi. Pusdatin Kementerian Pertanian. Jakarta.

Riduwan dan Akdon. 2015. Rumus dan Data dalam Aplikasi Statistika. Alfabeta. Bandung.

Sembiring, H., dan S. Abdurachman. 2008. Potensi Penerapan dan Pengembangan PTT dalam Upaya Peningkatan Produksi Padi. Jurnal Iptek Tanaman Pangan 3(2) : 278281. Kementrian Pertanian. Jakarta.

Suharsimi, A. 2010. Prosedur Penelitian Suatu Pendekatan Praktek. Rhineka Cipta. Jakarta. 